\title{
Alcohol abuse increases the risk of HIV infection and diminishes health status of clients attending HIV testing services in Vietnam
}

\author{
Bach Xuan Tran ${ }^{1,2^{*}}$, Long Hoang Nguyen ${ }^{1,3}$, Cuong Tat Nguyen ${ }^{4}$, Huong Thu Thi Phan ${ }^{5}$ and Carl A. Latkin ${ }^{2}$
}

\begin{abstract}
Background: Vietnam is among those countries with the highest drinking prevalence. In this study, we examined the prevalence of alcohol use disorders (AUDs) and its associations with HIV risky behaviors, health care utilization, and health-related quality of life (HRQOL) among clients using voluntary HIV testing and counseling services (VCT).

Methods: A cross-sectional survey of 365 VCT clients (71\% male; mean age 34) was conducted in Hanoi and Nam Dinh province. AUD and HRQOL were measured using the Alcohol Use Disorders Identification Test-Consumption (AUDIT-C), and EuroQol-five dimensions-five levels (EQ-5D-5L). Risky sexual behaviors, concurrent opioid use, and inpatient and outpatient service use were self-reported.

Results: $67.2 \%$ clients were lifetime ever drinkers of those $62.9 \%$ were hazardous drinkers and $82.0 \%$ were binge drinkers. There were $48.8 \%$ respondents who had $\geq 2$ sex partners over the past year and 55.4, 38.3, and $46.1 \%$ did not use condom in the last sex with primary/casual/commercial sex partners, respectively. Multivariate models show that AUD was significantly associated with risky sexual behaviors, using inpatient care and lower HRQOL among VCT clients.

Conclusions: AUD was prevalent, was associated with increased risks of HIV infection, and diminished health status among VCT clients. It may be efficient to screen for AUD and refer at-risk clients to appropriate AUD counseling and treatment along with HIV-related services.
\end{abstract}

Keywords: Alcohol, Sex, Drug use, AUDIT-C, HIV testing, Vietnam

\section{Background}

Vietnam is among those countries with the highest drinking prevalence in the world [1]. Drinking alcohol is legally and culturally accepted in Vietnamese traditions, especially among men $[2,3]$. A nationally representative survey revealed that $80 \%$ of males drank alcohol and $40 \%$ were hazardous drinkers compared to under $5 \%$ of female [4]. In the rural of Vietnam, $87.3 \%$ male and $10.2 \%$ female reported drinking alcohol in the last 12 months [5].

\footnotetext{
* Correspondence: bach@hmu.edu.vn

${ }^{1}$ Institute for Preventive Medicine and Public Health, Hanoi Medical University, Hanoi, Vietnam

${ }^{2}$ Johns Hopkins Bloomberg School of Public Health, Baltimore, MD, USA

Full list of author information is available at the end of the article
}

Among people living with HIV (PLWH), high alcohol consumption is associated with treatment nonadherence and poor immunological and viral outcomes $[6,7]$. In addition, drinking alcohol is associated with physical and mental problems such as neuropathy pain [8], lipodystrophy [9], and depression [10]. In Vietnam, alcohol consumption and alcohol use disorders (AUDs) have been found to negatively affect adherence to HIV medication and health-related quality of life (HRQOL) of patients with HIV/AIDS [2, 3, 11, 12]. However, the relationship between alcohol use and higher HIV risk behaviors has not been studied. In many other settings, alcohol abuse and its relations to HIV transmission have been well documented [13-18]. Heavy alcohol drinkers were more likely to engage in unsafe sexual behaviors, 
have multiple sex partners, or share syringes that increased the risk of HIV and other sexual transmitted infection (STI) transmissions [19-23].

The HIV epidemic in Vietnam is still in a concentrated stage, which is mostly driven by at-risk populations such as people who inject drug (PWID) and female sex workers [24] [25]. Although unsafe drug injection has been a predominant mode of transmission, there has been a significant increase of new cases got infected with HIV by unsafe sex [24]. Several studies have revealed socioeconomic and geographical differences that shape health behaviors as well as access, use, and outcomes of HIV/AIDS interventions in Vietnam. Kaljee et al. (2005) found that alcohol use is associated with intention and engagement in sexual behaviors among rural adolescents [26]. Nguyen et al. (2014) found higher odds of drug use among those motorbike taxi drivers who were born in urban cities, currently residing in rural areas, and using alcohol [27]. In addition, patients in the rural and urban perceived quality of care and reported health-related quality of life outcomes disproportionally [2, 28-32]. In the rapid urbanization of Vietnam, alcohol production and consumption has significantly changed. While urbanized people prefer branded products, mainly beer, the traditional alcohol drinking is common among older people in rural areas [33]. As a result, it is necessary to characterize how health behaviors and associated factors differ between urban and rural people to inform contextualized interventions in Vietnam.

Scaling-up HIV voluntary counseling and testing (VCT) service has been a priority of HIV/AIDS prevention programs in Vietnam [34]. In previous study, we founded that although only $4.1 \%$ VCT clients were current opiate users, the prevalence of people having risky sexual behaviors was very high [35]. We hypothesized that AUD might be a significant predictor of unsafe sex and other health problems among MMT clients. In addition, these risk behaviors might vary across diverse socioeconomic groups, for example gender and location. The current study assessed alcohol use prevalence among VCT clients and examined associations between AUDs and sexual risk behaviors as well as HRQOL and health care service utilization among respondents.

\section{Methods}

\section{Study setting and sampling}

A cross-sectional study was conducted in Hanoi and Nam Dinh from January to August 2013. Six VCT clinics were purposely selected by the following criteria: (1) involve facilities at provincial, district, and commune levels [36, 37]; (2) implementing VCT services according to national guidelines [38]; and (3) consisting of both urban and rural areas. In Vietnam, commune health station is a "gate-keeper" that provides basic medical care and implements public health programs [36, 37]. To recruit participants, a recruiter invited clients from the selected VCT clinics to participate in the study.

Eligibility of sampling included (1) clients aged 18 or above, (2) initiating the service or returning for the test results, and (3) able and willing to answer questions and provided written informed consent. The interviews were conducted in a private room by either counselors at the VCT clinics or well-trained researcher staffs.

\section{Measures and instruments}

A structured questionnaire was developed to examine alcohol use disorders and risk behaviors. We reviewed the literature to define factors that might be related to these outcomes of interest, including socioeconomic status, health status, history of drug use, and VCT service utilization [20, 22, 23]. In addition, we also assessed the interaction between alcohol use and gender [22].

\section{Socioeconomic status}

Information about age, gender, marital status, educational level, employment, religion, and household income were collected. Household income per capita was measured by estimating from all sources of income of all family members and then categorized into five quintiles: poorest, poor, middle, rich, and richest.

\section{Health status}

The EuroQol-five dimensions-five levels (EQ-5D-5L) instrument [39] was used to assess HRQOL of VCT clients. The Vietnamese version of this instrument has showed good measurement properties in this patient group [12, 32]. It includes five domains: mobility, selfcare, usual activities, pain/discomfort, and anxiety/depression with five responses from "no problem" to "extreme problem." By combining all domains and responses, a total health status index was created. Since the population's norms for Vietnam are unavailable, we used the interim scoring of EQ-5D-5L from a cross-walk value set from Thailand [39]. In addition, a visual analog scale (EQ-VAS) was used to evaluate the self-rate health of participants on a $20-\mathrm{cm}$ vertical scale. The score of EQ-VAS ranges $(0 ; 100)$ from "the worst health you can imagine" to "the best health you can imagine."

Additionally, we collected data about self-reported HIV status, which was categorized into three groups: HIV positive, HIV negative, and non-available or unknown (N/A).

\section{Alcohol abuse}

A brief instrument, the Alcohol Use Disorders Identification Test-Consumption (AUDIT-C), was used to screen heavy drinker and alcohol abuse [40]. The Vietnamese version of this tool was used and validated 
elsewhere $[3,41]$. It consists of three questions contributing to a band score of $(0 ; 12)$, with a higher score corresponding to a higher risk of alcohol dependence. If male respondents had score $\geq 4$ and female respondents had score $\geq 3$, they were categorized as hazardous drinkers [40]. The respondents were also classified as binge drinkers if the last item of the instrument received any positive response [42].

\section{Sexual behaviors measure}

Included information about whether clients ever had sexual intercourse, the number of sex partners in the last 12 months, types of sex partner (primary, casual, commercial), and condom use in the last sexual intercourse with each type of partner in the past 30 days.

\section{Opiate drug use behaviors}

Included information on historical and current drug use. Current drug use was defined if the clients used illicit opioid drug within the past 30 days.

\section{VCT and health services utilization}

We collected information about the frequency of VCT use, clients' referrers, willingness to refer their partners or relatives to VCT, and willingness to be voluntary peer educators. Inpatient and outpatient health care utilization in the past 12 months were also collected.

\section{Statistical analysis}

$P$ value $<0.05$ was considered statistical significance. Student $t$ test and $\chi^{2}$ tests were used to evaluate the difference of characteristics between resident areas (urban and rural). Multivariate logistic regression was employed to determine the associated factors with outcomes of interests, including "having multiple sexual partners in the last 30 days," "non condom use in the last sex with primary/casual/commercial sex partners," "outpatient services use," and "inpatient services use." Additionally, the range of EQ-5D index and EQ-VAS was left- and rightcensored since their score ranged at $(-0.452 ; 1)$ and $(0$; 100). The censored data limits the accurate estimation of values that are below and above the thresholds. Therefore, we used censored regression (Tobit) models to identify factors associated with EQ-5D index and EQVAS. The reduced model was constructed using stepwise backward selection, which was based on log-likelihood ratio tests with $p$ value $>0.2$ as a threshold for exclusion.

\section{Ethical approval}

The research was approved by the Scientific and Ethical Committee of the Authority for HIV/AIDS Control at the Vietnamese Ministry of Health.

\section{Results}

Of 365 VCT clients, the mean age was 34.0 ( $\mathrm{SD}=8.4$ ). There was no different between age and marital status between urban and rural respondents $(p>0.05)$. In urban areas, the proportion of male clients $(71.1 \%)$ was significantly higher than in rural areas $(57.6 \%)(p=0.02)$. The employment status and education attainment were also significantly different between the two groups $(p<0.01)$.

Table 1 reveals that the proportions of people having any problem in mobility, self-care, and usual activities in rural were significantly higher than people in urban areas $(p<0.01)$, while the prevalence of having problem in anxiety/depression among urban clients $(75.6 \%)$ was much higher than those in rural areas $(48.5 \%)(p<0.01)$. The mean EQ-5D index and EQ-VAS was $0.78(\mathrm{SD}=0.16)$ and 85.6 (SD = 13.7), respectively. About $4.7 \%$ were HIV positive, with no difference between urban (5.6\%) and rural $(2.0 \%)$ groups $(p=0.07)$.

Alcohol consumption is presented in Table 1. About two thirds of clients drank alcohol monthly or more; $36.5 \%$ had three drinks or more on a typical day and $55.5 \%$ ever drank six drinks or more on one occasion. Among 245 drinkers, $62.9 \%$ were hazardous drinkers and $82.0 \%$ were binge drinkers.

Table 2 shows that $90.9 \%$ of rural clients and $96.6 \%$ of urban clients ever had sex $(p=0.03)$. The proportion of respondents having multiple sexual partners in the past 12 months was higher in the urban (48.8\%) than in the rural (13.2\%). About 55.4, 38.3, and $46.1 \%$ respondents did not use condom in the last sex with primary, casual, and commercial sex partners, respectively. Table 2 also describes the proportion of people ever using drug in the urban, which were three times higher than in the rural areas $(p=0.02)$. About $8.7 \%$ urban clients ever injected drug compared to only $2.0 \%$ rural clients ( $p=$ $0.03)$. However, there was no difference in current drug use between two groups.

Table 3 provides information on VCT use amongst respondents. The average number of times of VCT utilization was $1.12(95 \% \mathrm{CI}=0.93-1.31)$, and there was no difference between rural and urban samples. Spouse and self-motivation were primary reasons for initial VCT used in rural, while peers and media were main motivators in urban $(p<0.01)$. No difference about referring partners to HIV testing services was found between both groups $(p=0.26)$, while the proportion of urban clients being willing to refer other relatives or voluntary peer instructors were significantly higher than rural clients $(p<0.05)$. About 20 and $10.1 \%$ of respondents used outpatient and inpatient care services in the last 12 months, respectively, with no difference between rural and urban.

Table 4 presents the reduced multivariate logistic regression models. Clients living with spouse/partners, 
Table 1 Alcohol use and health status of VCT clients in $2013(n=365)$

\begin{tabular}{|c|c|c|c|c|c|c|c|}
\hline & \multicolumn{2}{|l|}{ Rural } & \multicolumn{2}{|l|}{ Urban } & \multicolumn{2}{|l|}{ Total } & \multirow[t]{2}{*}{$p$} \\
\hline & $N$ & $\%$ & $N$ & $\%$ & $N$ & $\%$ & \\
\hline \multicolumn{8}{|l|}{ Frequency of drinking alcohol } \\
\hline Never & 40 & 40.4 & 80 & 30.1 & 120 & 32.9 & \multirow[t]{5}{*}{0.2} \\
\hline Never a month or less & 24 & 25.3 & 65 & 24.4 & 90 & 24.7 & \\
\hline Never 2-4 times/month & 20 & 20.2 & 69 & 25.9 & 89 & 24.4 & \\
\hline Never 2-3 times/week & 13 & 13.1 & 40 & 15 & 53 & 14.4 & \\
\hline Never $\geq 4$ times/week & 1 & 1.0 & 12 & 4.5 & 13 & 3.6 & \\
\hline \multicolumn{8}{|c|}{ Amount of drinks containing alcohol on typical day } \\
\hline Never $\leq 2$ & 91 & 91.9 & 141 & 53.0 & 232 & 63.5 & \multirow[t]{5}{*}{$<0.01$} \\
\hline Never 3 or 4 & 6 & 6.1 & 69 & 25.9 & 75 & 20.5 & \\
\hline Never 5 or 6 & 2 & 2.0 & 42 & 15.8 & 44 & 12.1 & \\
\hline Never 7 or 9 & 0 & 0.0 & 2 & 0.8 & 2 & 0.6 & \\
\hline Never $\geq 10$ & 0 & 0.0 & 12 & 4.5 & 12 & 3.3 & \\
\hline \multicolumn{8}{|c|}{ Frequency of drinking $\geq 6$ drinks on one occasion } \\
\hline Never & 67 & 67.7 & 97 & 36.4 & 164 & 44.8 & \multirow[t]{5}{*}{$<0.01$} \\
\hline Less than a month & 18 & 18.2 & 94 & 35.3 & 112 & 30.7 & \\
\hline Monthly & 12 & 12.1 & 46 & 17.3 & 58 & 15.9 & \\
\hline Weekly & 2 & 2.0 & 27 & 10.2 & 29 & 8 & \\
\hline Daily or almost daily & 0 & 0.0 & 2 & 0.8 & 2 & 0.6 & \\
\hline Hazardous drinkers (\# ever drinkers 245) & 22 & 37.3 & 132 & 71.0 & 154 & 62.9 & $<0.01$ \\
\hline Binge drinkers (\# ever drinkers = 245) & 32 & 54.2 & 168 & 90.9 & 201 & 82.0 & $<0.01$ \\
\hline \multicolumn{8}{|l|}{ Health status } \\
\hline Have problems in mobility & 37 & 37.4 & 58 & 21.8 & 95 & 26.0 & $<0.01$ \\
\hline Have problems in self-care & 24 & 24.2 & 6 & 2.3 & 30 & 8.2 & $<0.01$ \\
\hline Have problems in usual activities & 36 & 36.4 & 13 & 4.9 & 49 & 13.4 & $<0.01$ \\
\hline Have problems in pain/discomfort & 44 & 44.4 & 87 & 32.7 & 131 & 35.9 & 0.04 \\
\hline Have problems in anxiety/depression & 48 & 48.5 & 201 & 75.6 & 249 & 68.2 & $<0.01$ \\
\hline \multirow[t]{2}{*}{ HIV positive } & 2 & 2.0 & 15 & 5.6 & 17 & 4.7 & \multirow[t]{2}{*}{0.07} \\
\hline & Mean & SD & Mean & SD & Mean & SD & \\
\hline EuroQOL-5 dimensions (EQ5D) index & 0.77 & 0.23 & 0.78 & 0.13 & 0.78 & 0.16 & 0.68 \\
\hline Visual analog scale score (VAS) & 82.8 & 16.7 & 86.6 & 12.2 & 85.6 & 13.7 & 0.05 \\
\hline
\end{tabular}

having problems in anxiety, reporting higher EQ-VAS, using VCT services in urban clinics, and volunteering to be a peer instructor were more likely to have more than two sex partners, while people having HIVinfected spouse were less likely to have multiple partners. Additionally, the interaction between gender and alcohol consumption increased the likelihood of having more than two sex partners. Specifically, clients who reported being male and not hazardous drinkers (adjusted odd ratio $(\mathrm{AOR})=6.21,95 \% \mathrm{CI}=2.62-$ 14.72) or both male and hazardous drinkers $(\mathrm{AOR}=$ 4.92; $95 \% \mathrm{CI}=2.31-10.47)$ were more likely to have multiple sex partners compared to group with female only.
Table 4 also shows that employment and urban residence were associated with non-condom use with primary partners, while HIV-positive status and having HIVpositive relatives were associated with increased likelihood of condom use with primary partners. Clients who were white collar reported any problem in pain/discomfort and reported higher number of VCT use, and urban resident were less likely to use condom with casual partners than others. Also, male sex and hazardous drinking were positively associated with non-use condom with commercial partners (AOR $=2.35 ; 95 \% \mathrm{CI}=1.04-5.33$ ).

Factors associated with HRQOL and health care service use are displayed in Table 5. People having pain/discomfort and anxiety/depression problem, drinking three 
Table 2 Sexual risk behaviors and history of drug use among VCT clients in $2013(n=365)$

\begin{tabular}{|c|c|c|c|c|c|c|c|}
\hline \multirow[t]{2}{*}{ Factors } & \multicolumn{2}{|c|}{ Rural } & \multicolumn{2}{|c|}{ Urban } & \multicolumn{2}{|c|}{ Total } & \multirow{2}{*}{$\begin{array}{l}p \\
\text { value }\end{array}$} \\
\hline & N & $\%$ & N & $\%$ & N & $\%$ & \\
\hline Ever had sex & 90 & 90.9 & 257 & 96.6 & 347 & 95.1 & 0.03 \\
\hline \multicolumn{8}{|c|}{ Number of sex partners (in the last 12 months) } \\
\hline Not had anyone & 34 & 34.3 & 18 & 6.8 & 52 & 14.3 & $<0.01$ \\
\hline One sex partners & 52 & 52.5 & 118 & 44.4 & 170 & 46.6 & \\
\hline $2-3$ sex partners & 6 & 6.1 & 94 & 35.3 & 100 & 27.4 & \\
\hline$>4$ sex partners & 7 & 7.1 & 36 & 13.5 & 43 & 11.8 & \\
\hline \multicolumn{8}{|l|}{ Type of sex partners } \\
\hline Primary partners & 68 & 68.7 & 238 & 89.5 & 306 & 83.8 & $<0.01$ \\
\hline Casual sex partners & 0 & 0.0 & 64 & 24.1 & 64 & 17.5 & $<0.01$ \\
\hline Sex workers & 16 & 16.2 & 64 & 24.1 & 80 & 21.9 & 0.10 \\
\hline \multicolumn{8}{|l|}{ Non-condom use with last sex } \\
\hline With primary sex partners $(n=305)$ & 42 & 62.3 & 127 & 53.4 & 169 & 55.4 & 0.18 \\
\hline With casual sex partners $(n=60)$ & 0 & 0.0 & 23 & 38.3 & 23 & 38.3 & - \\
\hline With sex workers $(n=76)$ & 16 & 100.0 & 19 & 31.7 & 35 & 46.1 & $<0.01$ \\
\hline Ever drug use & 4 & 4.0 & 34 & 12.8 & 38 & 10.4 & 0.02 \\
\hline Ever inject drug & 2 & 2.0 & 23 & 8.7 & 25 & 6.9 & 0.03 \\
\hline Current drug use & 2 & 50.0 & 13 & 38.2 & 15 & 39.5 & 0.65 \\
\hline
\end{tabular}

Table 3 Health care and VCT services utilization of respondents in $2013(n=365)$

\begin{tabular}{|c|c|c|c|c|c|c|c|c|c|c|}
\hline \multirow[b]{3}{*}{ VCT service utilization (total times) } & \multicolumn{3}{|l|}{ Rural } & \multicolumn{3}{|l|}{ Urban } & \multicolumn{3}{|l|}{ Total } & \multirow{3}{*}{$\begin{array}{l}p \\
\text { value } \\
0.17\end{array}$} \\
\hline & \multirow{2}{*}{$\begin{array}{l}\text { Mean } \\
1.02\end{array}$} & \multicolumn{2}{|c|}{$95 \% \mathrm{Cl}$} & \multirow{2}{*}{$\frac{\text { Mean }}{1.16}$} & \multicolumn{2}{|c|}{$95 \% \mathrm{Cl}$} & \multirow{2}{*}{$\frac{\text { Mean }}{1.12}$} & \multicolumn{2}{|c|}{$95 \% \mathrm{Cl}$} & \\
\hline & & 0.68 & 1.36 & & 0.92 & 1.39 & & 0.93 & 1.31 & \\
\hline & $n$ & $\%$ & & $n$ & $\%$ & & $n$ & $\%$ & & \\
\hline \multicolumn{11}{|l|}{ Referrer of the first VCT used } \\
\hline Spouse & 22 & 44.0 & & 14 & 8.9 & & 36 & 17.4 & & $<0.01$ \\
\hline Peers & 5 & 10.0 & & 48 & 30.6 & & 53 & 25.6 & & \\
\hline Health workers & 2 & 4.0 & & 21 & 13.4 & & 23 & 11.1 & & \\
\hline Media & 7 & 14.0 & & 47 & 29.9 & & 54 & 26.1 & & \\
\hline Self-motivation & 9 & 18.0 & & 22 & 14.0 & & 31 & 15 & & \\
\hline Parents/relatives & 5 & 10.0 & & 5 & 3.2 & & 10 & 4.8 & & \\
\hline \multicolumn{11}{|l|}{ HIV status (positive) } \\
\hline Individual & 2 & 4.0 & & 15 & 9.0 & & 17 & 4.7 & & 0.12 \\
\hline Spouse/partners & 29 & 29.2 & & 12 & 4.5 & & 41 & 11.2 & & $<0.01$ \\
\hline Parents & 1 & 1.0 & & 0 & 0.0 & & 1 & 0.3 & & 0.1 \\
\hline Brother/sister & 5 & 5.1 & & 3 & 1.1 & & 8 & 2.2 & & 0.02 \\
\hline Other relatives & 1 & 1.0 & & 12 & 5.5 & & 13 & 3.5 & & 0.2 \\
\hline Refer partners to HIV testing services & 54 & 57.5 & & 166 & 64.1 & & 220 & 60.3 & & 0.26 \\
\hline Refer other relatives to HIV testing services & 40 & 43.0 & & 148 & 57.1 & & 188 & 51.5 & & 0.02 \\
\hline Volunteer to be a peer Instructor & 14 & 14.9 & & 81 & 31.2 & & 95 & 26.8 & & 0.01 \\
\hline \multicolumn{11}{|l|}{ Health service use } \\
\hline Outpatient service use in the last 12 months & 15 & 15.2 & & 58 & 21.8 & & 73 & 20.0 & & 0.16 \\
\hline Inpatient service use in the last 12 months & 5 & 5.1 & & 32 & 12.0 & & 37 & 10.1 & & 0.05 \\
\hline
\end{tabular}


Table 4 Factors associated with sexual risk behaviors among VCT clients in multivariate regression $(n=365$; year 2013)

\begin{tabular}{|c|c|c|c|c|c|c|c|c|c|c|c|c|}
\hline \multirow[t]{2}{*}{ Factors } & \multicolumn{3}{|c|}{$\begin{array}{l}\text { Having } \geq 2 \text { sexual } \\
\text { partners within } \\
12 \text { months }\end{array}$} & \multicolumn{3}{|c|}{$\begin{array}{l}\text { Not use condom } \\
\text { in the last sex } \\
\text { with primary } \\
\text { partners }\end{array}$} & \multicolumn{3}{|c|}{$\begin{array}{l}\text { Not use condom } \\
\text { in the last sex } \\
\text { with casual } \\
\text { partners } \\
\end{array}$} & \multicolumn{3}{|c|}{$\begin{array}{l}\text { Not use condom } \\
\text { in the last sex with } \\
\text { sex workers }\end{array}$} \\
\hline & AOR & \multicolumn{2}{|c|}{$95 \% \mathrm{Cl}$} & $\mathrm{AOR}$ & \multicolumn{2}{|c|}{$95 \% \mathrm{Cl}$} & $A O R$ & \multicolumn{2}{|c|}{$95 \% \mathrm{Cl}$} & $\mathrm{AOR}$ & \multicolumn{2}{|c|}{$95 \% \mathrm{Cl}$} \\
\hline \multicolumn{13}{|l|}{ Occupation (vs unemployed) } \\
\hline Self-employed & & & & $3.55^{*}$ & 1.33 & 9.51 & & & & & & \\
\hline White collars & & & & $9.03^{*}$ & 3.24 & 25.17 & $2.41^{*}$ & 1.02 & 5.69 & & & \\
\hline Workers/farmers & & & & 2.66 & 0.95 & 7.49 & & & & & & \\
\hline Other jobs & & & & $7.23^{*}$ & 2.05 & 25.50 & & & & & & \\
\hline \multicolumn{13}{|l|}{ Marital status (vs single) } \\
\hline Live with spouse/partner & $1.90^{*}$ & 1.02 & 3.52 & & & & & & & & & \\
\hline \multicolumn{13}{|l|}{ Income quintile (vs poorest) } \\
\hline Poor & & & & & & & & & & 2.19 & 0.89 & 5.38 \\
\hline Richest & 0.48 & 0.23 & 1.00 & & & & & & & & & \\
\hline Have problems in usual activities (yes vs no) & & & & & & & & & & $12.94^{*}$ & 1.93 & 86.96 \\
\hline Have problems in pain/discomfort (yes vs no) & & & & & & & $3.42^{*}$ & 1.50 & 7.78 & & & \\
\hline Have problems in anxiety/depression (yes vs no) & $2.75^{*}$ & 1.44 & 5.26 & & & & & & & & & \\
\hline EQ-VAS & $1.05^{*}$ & 1.02 & 1.08 & 1.02 & 1.00 & 1.04 & & & & & & \\
\hline HIV positive (yes vs no) & & & & $0.54^{*}$ & 0.30 & 0.99 & & & & & & \\
\hline \multicolumn{13}{|c|}{$\begin{array}{l}\text { Interaction between alcohol and gender (vs female }+ \text { no hazardous } \\
\text { drinkers) }\end{array}$} \\
\hline Male + no hazardous drinkers & $6.21^{*}$ & 2.62 & 14.72 & & & & & & & & & \\
\hline Male + hazardous drinkers & $4.92^{*}$ & 10.47 & & & & & & & & $2.35^{*}$ & 1.04 & 5.33 \\
\hline Number of VCT services uses (times) & & & & & & & $1.34^{*}$ & 1.11 & 1.61 & & & \\
\hline Not have HIV-positive member in family (yes vs no) & & & & $0.42^{*}$ & 0.22 & 0.78 & & & & & & \\
\hline Have HIV-infected spouses (yes vs no) & $0.10^{*}$ & 0.01 & 0.86 & & & & & & & & & \\
\hline Refer relatives to HIV testing services (yes vs no) & & & & 1.58 & 0.88 & 2.83 & & & & & & \\
\hline Volunteer to be a peer instructor (yes vs no) & $3.73^{*}$ & 1.84 & 7.55 & & & & & & & & & \\
\hline Service location area (urban vs rural) & $8.04^{*}$ & 3.21 & 20.14 & $2.02^{*}$ & 1.05 & 3.91 & $6.12^{*}$ & 1.36 & 27.45 & & & \\
\hline
\end{tabular}

AORadjusted odd ratio, EQ-VAS EuroQOL-visual analog scale ${ }^{*} p<0.05$

to four drinks, and drinking $\geq 6$ drinks in less than a month were more likely to use inpatient care in the last 12 months. Meanwhile, higher income and having problems in usual activities and pain/discomfort were positive factors for the use of outpatient services.

The results of Table 5 also show that outpatient and inpatient service use as well as referring partners to HIV testing services was associated with lower HRQOL measured using the EQ-5D composite index. In addition, people having HIV-positive status, drinking alcohol $\geq 4$ times/week, current opiate users, utilizing outpatient service, and higher number of VCT use were more likely to report lower EQ-VAS scores. Meanwhile inconsistent condom use with primary partner, not having HIVpositive member in family, and referring relatives to HIV testing were associated with higher EQ-VAS scores among clients.

\section{Discussion}

This study reveals a high prevalence of AUDs among VCT clients and contributes to the growing body of evidence on the association between alcohol abuse and HIV-risk behaviors, lower HRQOL, and increased health care service use [19-23]. In the context of Vietnam where alcohol plays a vital part in the culture, these results provide implications for developing interventions to reduce the burden of alcohol use and HIV/AIDS.

In this study, we observed that $67.1 \%$ VCT clients drank alcohol, of those hazardous drinkers accounted for $62.9 \%$ ( $42.2 \%$ in the whole sample). This figure was much higher than in general Vietnamese population. For example, a study by Giang et al. (2008) suggested that $25.5 \%$ male and $0.7 \%$ female had AUDs [5]. This prevalence was also much higher than that of patients with HIV/AIDS (30.1\% were hazardous drinkers) [3, 6], male 
Table 5 Factors associated with HRQOL and health care service use among VCT clients in multivariate regression $(n=365$; year 2013)

\begin{tabular}{|c|c|c|c|c|c|c|c|c|c|c|c|c|}
\hline \multirow[t]{2}{*}{ Factors } & \multicolumn{3}{|c|}{$\begin{array}{l}\text { Inpatient care } \\
\text { utilization in the } \\
\text { last } 12 \text { month }\end{array}$} & \multicolumn{3}{|c|}{$\begin{array}{l}\text { Outpatient care } \\
\text { utilization in the } \\
\text { last } 12 \text { months }\end{array}$} & \multicolumn{3}{|c|}{ EQ-5D Index ${ }^{a}$} & \multicolumn{3}{|l|}{ EQ-VAS $^{a}$} \\
\hline & $\mathrm{AOR}$ & \multicolumn{2}{|c|}{$95 \% \mathrm{Cl}$} & $\mathrm{AOR}$ & \multicolumn{2}{|c|}{$95 \% \mathrm{Cl}$} & Coef & \multicolumn{2}{|c|}{$95 \% \mathrm{Cl}$} & Coef & \multicolumn{2}{|l|}{$95 \% \mathrm{Cl}$} \\
\hline \multicolumn{13}{|l|}{ Income quintile (vs poorest) } \\
\hline Poor & & & & & & & 0.07 & 0.01 & 0.13 & 4.72 & 0.38 & 9.06 \\
\hline Middle & & & & 2.53 & 0.98 & 6.51 & & & & & & \\
\hline Rich & & & & $4.85^{*}$ & 1.94 & 12.12 & & & & & & \\
\hline Richest & & & & $3.43^{*}$ & 1.38 & 8.51 & & & & & & \\
\hline Have problems in usual activities (yes vs no) & & & & $2.43^{*}$ & 1.02 & 5.78 & & & & & & \\
\hline Have problems in pain/discomfort (yes vs no) & $3.57^{*}$ & 1.46 & 8.71 & $5.13^{*}$ & 2.53 & 10.42 & & & & & & \\
\hline Have problems in anxiety/depression (yes vs no) & $10.91^{*}$ & 1.39 & 85.66 & & & & & & & & & \\
\hline \multicolumn{13}{|l|}{ HIV status (vs negative) } \\
\hline Positive & & & & & & & & & & $-4.79 *$ & -8.96 & -0.63 \\
\hline \multicolumn{13}{|l|}{ Frequency of drinking alcohol (vs never) } \\
\hline$\geq 4$ times/week & & & & & & & & & & $-9.61^{*}$ & -18.93 & -0.30 \\
\hline \multicolumn{13}{|l|}{$\begin{array}{l}\text { Amount of drinks containing alcohol on typical day (vs } \leq 2 \\
\text { drinks) }\end{array}$} \\
\hline 3 or 4 & $2.85^{*}$ & 1.13 & 7.23 & & & & & & & & & \\
\hline 5 or 6 & & & & & & & & & & 5.51 & -0.04 & 11.06 \\
\hline$\geq 10$ & & & & & & & & & & 10.27 & -0.08 & 20.63 \\
\hline \multicolumn{13}{|l|}{ Frequency of drinking $\geq 6$ drinks on one occasion (vs never) } \\
\hline Less than a month & $2.11^{*}$ & 1.08 & 4.15 & & & & 0.05 & -0.01 & 0.10 & & & \\
\hline Have $\geq 2$ sex partners in the last 12 months (yes vs no) & & & & & & & & & & $6.65^{*}$ & 2.95 & 10.36 \\
\hline Non-use condom in last sex with primary partners (yes vs no) & & & & & & & & & & 4.08 & 0.41 & 7.75 \\
\hline Current opiate users (yes vs no) & & & & & & & & & & $-11.46^{*}$ & -19.33 & -3.59 \\
\hline Outpatient care utilization in the last 12 months (yes vs no) & & & & & & & $-0.11^{*}$ & -0.18 & -0.04 & $-7.69^{*}$ & -12.00 & -3.39 \\
\hline Inpatient care utilization in the last 12 months (yes vs no) & & & & & & & $-0.11^{*}$ & -0.20 & -0.02 & & & \\
\hline Number of VCT services uses (times) & & & & & & & & & & $-1.17^{*}$ & -2.10 & -0.25 \\
\hline Not have HIV-positive member in family (yes vs no) & & & & & & & & & & $3.98^{*}$ & 0.08 & 7.87 \\
\hline Refer partners to HIV testing services (yes vs no) & & & & & & & $-0.07^{*}$ & -0.13 & -0.02 & & & \\
\hline Refer relatives to HIV testing services (yes vs no) & & & & & & & & & & $4.92^{*}$ & 1.27 & 8.56 \\
\hline
\end{tabular}

AOR adjusted odd ratio, EQ-5D EuroQOL-5 dimensions, EQ-VAS EuroQOL-visual analog scale ${ }^{\mathrm{a}}$ Tobit regression model ${ }^{*} p<0.05$

sex workers (29\%), and female sex workers (11\%) [43]. In addition, the association between AUDs and sexual risk behaviors was consistent with previous studies of Vietnam and worldwide [19-23, 44-46]. Having multiple sexual partners [47], inconsistent condom use, and sexually transmitted infections (STIs) were more prevalent among people with AUDs $[48,49]$. The prevalence of female having AUDs in this study was much lower than male clients ( 2.5 vs $61.4 \%$, respectively). The association between AUD and sexual risk behaviors has been observed in other countries. Carey et al. found that a high level of alcohol consumption may predict the number of sexual partners among female [22]. Another study by Hutton showed that binge drinking was related to risky sexual behaviors and STIs among female, but no association was observed among male [50].

Interestingly, the finding suggested that people who had health problems in usual activities, pain/discomfort and anxiety/depression were more likely to engage in risky sexual behaviors. In the literature, depression and mental health disorders have been found to be associated with unsafe sexual activities [22, 51]. Depression may lead to psychosocial and cognitive impairment [52] that diminishes the ability of patients to prevent risk behavior. Also, risky sexual behaviors may be stigmatized and may lead to depression [51]. 
In line with previous studies [53, 54], we also found that AUD was associated with decrements in HRQOL and health care service use among VCT clients [55]. The results of this study suggest a need for interventions to reduce the alcohol consumption and facilitate protected sex behaviors as well as drug use abstinence. VCT providers should incorporate the screen of alcohol use problems into their counseling session, offer appropriate information on the harms associated with alcohol use, and provide counseling or treatment service referrals for alcohol as well as other types of substance abuse. This intervention is more important for those who were diagnose with HIV since alcohol and drug abuse are significantly associated with poor adherence and outcomes of HIV/AIDS care and treatment services $[6,7,11,12,31$, 32, 56-58]. Second, since VCT clients may experience multiple health problems, including behavioral health issues, health care providers should be aware of complicated health care needs of clients and integrative facilities that provide VCT with general health care, and HIV-related services are important models to improve the efficiency of health services delivery system $[28,59$, 60]. Third, findings of this study highlight the multidimensional impacts of high alcohol consumption in Vietnam including not only increased health risks but also higher demand for health care services. Harm reduction policies to reduce alcohol consumption in the country should be contextualized for different settings and focus on raising awareness of community on corresponding health and economic outcomes associated with at-risk alcohol use.

The strength of this study comprises a multiple site sample in two provinces with large HIV epidemics in Vietnam. In addition, the use of an international screening tool for AUD (AUDIT-C), which was validated in Vietnamese settings, has improved the validity of assessment instrument $[2,3]$. Also, it helps increase the comparability of the results with other studies in Vietnam and elsewhere. However, there are several limitations that should be acknowledged. First, a convenience sampling limits the representativeness of the study findings. Second, the sample size was small, which may affect the statistical power. Third, information was self-reported, which might lead to recall bias. Finally, the causal relationship between AUD and risk behaviors could not be established due to cross-sectional nature of the study.

\section{Conclusions}

In conclusion, AUD was prevalent, increases the risk of HIV transmission, and diminishes health status of VCT clients. Screening and intervening on alcohol abuse for VCT clients, as well as providing VCT along with general health care services, may improve the efficiency of health service delivery system in Vietnam.

\section{Competing interests}

The authors declare that they have no competing interests.

\section{Authors' contributions}

BXT, HTTP, CL, LHN, and CTN conceived the study and participated in its design and implementation, and wrote the manuscript. LHN and CTN analyzed the data. BXT, LHN, HTTP, CL, and CTN helped to draft the manuscript. All authors read and approved the final manuscript.

\section{Acknowledgements}

The authors would like to acknowledge supports by the Vietnam Authority of HIV/AIDS Control for the use of this survey data. There was no funding for this analysis.

\section{Author details}

${ }^{1}$ Institute for Preventive Medicine and Public Health, Hanoi Medical University, Hanoi, Vietnam. ${ }^{2}$ Johns Hopkins Bloomberg School of Public Health, Baltimore, MD, USA. ${ }^{3}$ School of Medicine and Pharmacy, Vietnam National University, Hanoi, Vietnam. ${ }^{4}$ Institute for Global Health Innovations, Duy Tan University, Da Nang, Vietnam. ${ }^{5}$ Authority of HIV/AIDS Control, Ministry of Health, Hanoi, Vietnam.

Received: 18 October 2015 Accepted: 22 January 2016

Published online: 16 February 2016

\section{References}

1. World Health Organization. Global status report on alcohol and health. Geneva, Switzerland: 2011.Available athttp://www.who.int/substance_abuse/ publications/global_alcohol_report/msbgsruprofiles.pdf. Accessed 1 June 2015.

2. Kraemer KL. Can a behavioral alcohol intervention be delivered costeffectively to persons living with HIV/AIDS in sub-Saharan Africa? Alcohol Clin Exp Res. 2016;40(1):50-1.

3. Tran BX, Nguyen N, Ohinmaa A, et al. Prevalence and correlates of alcohol use disorders during antiretroviral treatment in injection-driven HIV epidemics in Vietnam. Drug Alcohol Depend. 2013;127(1-3):39-44.

4. Bui TV, Blizzard CL, Luong KN, et al. Alcohol consumption in Vietnam, and the use of 'Standard Drinks' to measure alcohol intake. Alcohol and Alcoholism. 2015-07-08 00:00:00 2015.

5. Giang KB, Allebeck P, Spak F, Van Minh H, Dzung TV. Alcohol use and alcohol consumption-related problems in rural Vietnam: an epidemiological survey using AUDIT. Substance use \& misuse. 2008;43(3-4):481-95.

6. Hahn JA, Emenyonu NI, Fatch $\mathrm{R}$, et al. Declining and rebounding unhealthy alcohol consumption during the first year of HIV care in rural Uganda, using phosphatidylethanol to augment self-report. Addiction. 2016:111(2):272-9.

7. Neuman MG, Monteiro M, Rehm J. Drug interactions between psychoactive substances and antiretroviral therapy in individuals infected with human immunodeficiency and hepatitis viruses. Substance use \& misuse. 2006; 41(10-12):1395-463.

8. Ferrari LF, Levine JD. Alcohol consumption enhances antiretroviral painful peripheral neuropathy by mitochondrial mechanisms. Eur J Neurosci. 2010;32(5):811-8.

9. Cheng DM, Libman H, Bridden C, Saitz R, Samet JH. Alcohol consumption and lipodystrophy in HIV-infected adults with alcohol problems. Alcohol. 2009;43(1):65-71.

10. Ghebremichael M, Paintsil E, Ickovics JR, et al. Longitudinal association of alcohol use with HIV disease progression and psychological health of women with HIV. AIDS care. 2009;21(7):834-41.

11. Tran BX, Ohinmaa A, Nguyen LT, et al. Gender differences in quality of life outcomes of HIV/AIDS treatment in the latent feminization of HIV epidemics in Vietnam. AIDS Care. 2012;24(10):1187-96.

12. Tran BX, Ohinmaa A, Nguyen LT. Quality of life profile and psychometric properties of the EQ-5D-5L in HIV/AIDS patients. Health Qual Life Outcomes. 2012;10:132

13. Wray TB, Grin B, Dorfman L, et al. Systematic review of interventions to reduce problematic alcohol use in men who have sex with men. Drug Alcohol Rev. 2015. doi:10.1111/dar.12271.

14. Wirtz AL, Zelaya CE, Latkin C, et al. Alcohol use and associated sexual and substance use behaviors among men who have sex with men in Moscow, Russia. AIDS and behavior. 2015. doi:10.1007/s10461-015-1066-2. [Epub ahead of print]. 
15. Wandera B, Tumwesigye NM, Nankabirwa Jl, et al. Alcohol consumption among HIV-infected persons in a large urban HIV clinic in Kampala Uganda: a constellation of harmful behaviors. PloS one. 2015;10(5):e0126236.

16. Walter AW, Lundgren L, Umez-Eronini A, Ritter GA. Alcohol use and HIV testing in a national sample of women. AIDS Behav. 2016;20(Suppl 1):84-96. doi: 10.1007/s10461-015-1144-5.

17. Scott-Sheldon LA, Walstrom P, Carey KB, Johnson BT, Carey MP. Alcohol use and sexual risk behaviors among individuals infected with HIV: a systematic review and meta-analysis 2012 to early 2013. Current HIV/AIDS reports. 2013;10(4):314-23.

18. Rehm J, Shield KD, Joharchi N, Shuper PA. Alcohol consumption and the intention to engage in unprotected sex: systematic review and metaanalysis of experimental studies. Addiction. 2012;107(1):51-9.

19. Le Marchand C, Evans J, Page K, Davidson PJ, Hahn JA. Hazardous alcohol consumption among young adult IDU and its association with high risk behaviors. Drug Alcohol Depend. 2013;127(1-3):143-9.

20. Lu H, Han Y, He X, et al. Alcohol use and HIV risk taking among Chinese MSM in Beijing. Drug Alcohol Depend. 2013;133(2):317-23.

21. Li Q, Li X, Stanton B. Alcohol use and sexual risk behaviors and outcomes in China: a literature review. AIDS and behavior. 2010;14(6):1227-36.

22. Carey KB, Senn TE, Walsh JL, Scott-Sheldon LA, Carey MP. Alcohol use predicts number of sexual partners for female but not male STI clinic patients. AIDS Behav. 2016(Suppl 1):52-9. doi: 10.1007/s10461-015-1177-9.

23. Nayak MB, Korcha RA, Benegal V. Alcohol use, mental health, and HIVrelated risk behaviors among adult men in Karnataka. AIDS and behavior. 2010;14 Suppl 1:S61-73.

24. Control VAoHA. The annual review of HIV/AIDS control and prevention in the first six months 2015 and action plan in the last six months in 2015. Hanoi: Ministry of Health; 2015.

25. Control VAoHA. Vietnam HIV/AIDS estimates and projections 2011-2015. Hanoi: Ministry of Health; 2013.

26. Kaljee LM, Genberg BL, Minh TT, Tho LH, Thoa LT, Stanton B. Alcohol use and HIV risk behaviors among rural adolescents in Khanh Hoa Province Viet Nam. Health education research. 2005;20(1):71-80.

27. Nguyen HV, Vu TT, Pham HN. Factors associated with drug use among male motorbike taxi drivers in urban Vietnam. Substance use \& misuse. 2014; 49(10):1287-95.

28. Tran BX, Nguyen LH, Phan HT, Latkin CA. Patient satisfaction with methadone maintenance treatment in Vietnam: a comparison of different integrative-service delivery models. PloS one. 2015;10(11), e0142644.

29. Nguyen NP, Tran BX, Hwang LY, et al. Prevalence of cigarette smoking and associated factors in a large sample of HIV-positive patients receiving antiretroviral therapy in Vietnam. PloS one. 2015;10(2), e0118185.

30. Tran BX, Nguyen LT, Nguyen NP, Phan HT. HIV voluntary testing and perceived risk among female sex workers in the Mekong Delta region of Vietnam. Global health action. 2013;6:20690.

31. Tran BX. Quality of life outcomes of antiretroviral treatment for HIV/AIDS patients in Vietnam. PloS one. 2012;7(7), e41062.

32. Tran BX, Ohinmaa A, Nguyen LT, Nguyen TA, Nguyen TH. Determinants of health-related quality of life in adults living with HIV in Vietnam. AIDS Care. 2011;23(10):1236-45.

33. Luu BN, Nguyen TT, Newman IM. Traditional alcohol production and use in three provinces in Vietnam: an ethnographic exploration of health benefits and risks. BMC Public Health. 2014;14:731.

34. Ministry of Health, Vietnam. National strategy on HIV/AIDS prevention and control toward 2020 and the vision to 2030. Hanoi, Vietnam: 2012.

35. Nguyen LH, Tran BX, Nguyen NP, Phan HT, Bui TT, Latkin CA. Mobilization for HIV voluntary counseling and testing services in Vietnam: clients' risk behaviors, attitudes and willingness to pay. AIDS and behavior.Sep 122015. 10.1007/s10461-015-1188-6.

36. Nguyen TX, Tran BX, Arianna W, Christa H, Lars L. "Socialization of Health Care" in Vietnam: what is it and what are its pros and cons? Value in Health Regional Issues. 2014;3:24-6.

37. Tran BX, Van Hoang M, Nguyen HD. Factors associated with job satisfaction among commune health workers: implications for human resource policies. Global health action. 2013;6:1-6.

38. Ministry of Health, Vietnam. Decision No. 647/QD-BYT of 22 February 2007 on Promulgation of voluntary HIV counseling and testing (VCT) guidelines. Hanoi, Vietnam: 2007.

39. Group E. EQ-5D-5L user guide: basic information on how to use the EQ-5D-5L instrument. 2011; http://www.euroqol.org/fileadmin/user_
upload/Documenten/PDF/Folders_Flyers/UserGuide_EQ-5D-5L.pdf. Accessed 1-9, 2013.

40. Bradley KA, DeBenedetti AF, Volk RJ, Williams EC, Frank D, Kivlahan DR. AUDIT-C as a brief screen for alcohol misuse in primary care. Alcohol Clin Exp Res. 2007;31(7):1208-17.

41. Tran BX, Nguyen LT, Do CD, Nguyen QL, Maher RM. Associations between alcohol use disorders and adherence to antiretroviral treatment and quality of life amongst people living with HIV/AIDS. BMC public health. 2014;14(1):27.

42. Broyles LM, Gordon AJ, Sereika SM, Ryan CM, Erlen JA. Predictive utility of brief alcohol use disorders identification test (AUDIT) for human immunodeficiency virus antiretroviral medication nonadherence. Subst Abus. 2011;32(4):252-61.

43. Samet JH, Pace CA, Cheng DM, et al. Alcohol use and sex risk behaviors among HIV-infected female sex workers (FSWs) and HIV-infected male clients of FSWs in India. AIDS and behavior. 2010;14 Suppl 1:S74-83.

44. Hendershot CS, Stoner SA, George WH, Norris J. Alcohol use, expectancies, and sexual sensation seeking as correlates of HIV risk behavior in heterosexual young adults. Psychol Addict Behav. 2007;21(3):365-72.

45. Muchimba M, Haberstick BC, Corley RP, McQueen MB. Frequency of alcohol use in adolescence as a marker for subsequent sexual risk behavior in adulthood. J Adolesc Health. 2013;53(2):215-21.

46. le Tho $H$, Singhasivanon P, Kaewkungwal J, Kaljee LM, Charoenkul C. Sexual behaviors of alcohol drinkers and non-drinkers among adolescents and young adults in Nha Trang, Vietnam. Southeast Asian J Trop Med Public Health. 2007;38(1):152-60.

47. Woolf-King SE, Maisto SA. Alcohol use and high-risk sexual behavior in SubSaharan Africa: a narrative review. Archives of sexual behavior. 2011;40(1):17-42.

48. Carlson SR, Johnson SC, Jacobs PC. Disinhibited characteristics and binge drinking among university student drinkers. Addictive behaviors. 2010;35(3): 242-51.

49. Van Tieu H, Koblin BA. HIV, alcohol, and noninjection drug use. Current opinion in HIV and AIDS. 2009;4(4):314-8.

50. Hutton HE, McCaul ME, Santora PB, Erbelding EJ. The relationship between recent alcohol use and sexual behaviors: gender differences among sexually transmitted disease clinic patients. Alcohol Clin Exp Res. 2008;32(11):2008-15.

51. Khan MR, Kaufman JS, Pence BW, et al. Depression, sexually transmitted infection, and sexual risk behavior among young adults in the United States. Archives of pediatrics \& adolescent medicine. 2009;163(7):644-52.

52. Rao U. Links between depression and substance abuse in adolescents: neurobiological mechanisms. American journal of preventive medicine. 2006:31(6 Suppl 1):S161-174.

53. Foster JH, Powell JE, Marshall EJ, Peters TJ. Quality of life in alcoholdependent subjects - a review. Qual Life Res. 1999:8(3):255-61.

54. Donovan D, Mattson ME, Cisler RA, Longabaugh R, Zweben A. Quality of life as an outcome measure in alcoholism treatment research. J Stud Alcohol Suppl. 2005;15:119-39. discussion 192-113.

55. Azar MM, Springer SA, Meyer JP, Altice FL. A systematic review of the impact of alcohol use disorders on HIV treatment outcomes, adherence to antiretroviral therapy and health care utilization. Drug Alcohol Depend. 2010;112(3):178-93.

56. Tran BX, Ohinmaa A, Duong AT, et al. Changes in drug use are associated with health-related quality of life improvements among methadone maintenance patients with HIV/AIDS. Qual Life Res. 2012;21(4):613-23.

57. Tran BX, Ohinmaa A, Mills $\mathrm{S}$, et al. Multilevel predictors of concurrent opioid use during methadone maintenance treatment among drug users with HIV/AIDS. PloS one. 2012;7(12), e51569.

58. Tran BX, Nguyen LT, Nguyen NH, Hoang QV, Hwang J. Determinants of antiretroviral treatment adherence among HIV/AIDS patients: a multisite study. Global Health Action. 2013;6:19570.

59. Tran BX, Ohinmaa A, Duong AT, et al. Cost-effectiveness of integrating methadone maintenance and antiretroviral treatment for HIV-positive drug users in Vietnam's injection-driven HIV epidemics. Drug Alcohol Depend. 2012:125(3):260-6

60. Tran BX, Nguyen LH, Phan HT, Nguyen LK, Latkin CA. Preference of methadone maintenance patients for the integrative and decentralized service delivery models in Vietnam. Harm Reduction J. 2015;12(1):29. 